\title{
EFFECT OF SOME INSECTICIDES ON THE LIFE TABLE PARAMETERS OF THE PINK BOLLWORM, PECTINOPHORA GOSSYPIELLA (SAUND.)
}

\author{
EL-METWALLY, H. EL-SAID ${ }^{1}$, S. A. EL-MAHEY ${ }^{1}$, ALIA M. ABD EL-HAFEZ ${ }^{2}$ \\ AND R. A. M. AMER ${ }^{2}$
}

1. Depart. of Economic Entomol. \& Pesticide, Faculty of Agriculture, Cairo University, Giza, Egypt

2. Bollworms Depart., Plant Protection Research Institute, ARC, Dokki, Giza, Egypt

(Manuscript received 15 June 2006)

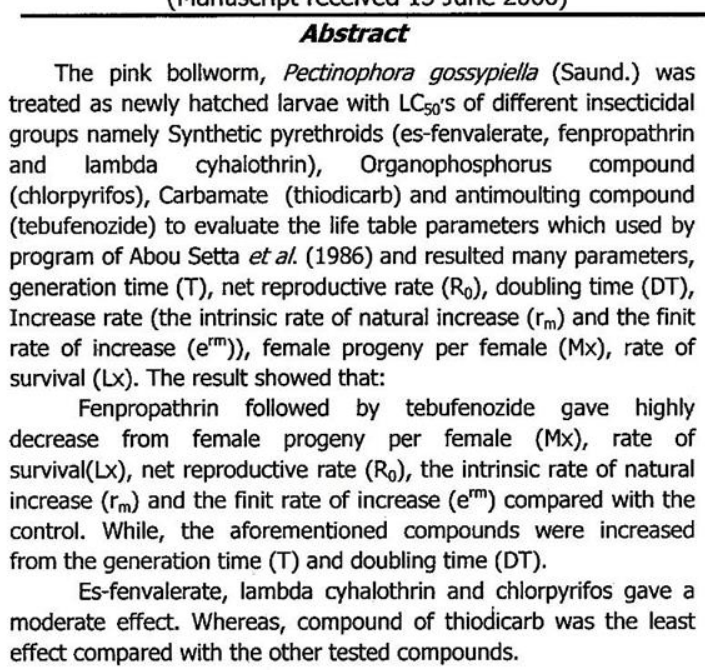

\section{INTRODUCTION}

The pink bollworm, Pectinophora gossypiella (Saund.) is the most destructive pest infesting cotton bolis through the world.

Life table parameters gives a measure of the relative suitability of different environment, also it gives the actual rate increase of the insect under different conditions. An index for the possible rate of the increase under different physical conditions would at the same time provide this in an index combining the total number of eggs laid, the survival rate of immature stages, the rate of development and the sex ratio. On the other hand, life tables are basic parameter which may be established for an insect population under specified physical conditions.

For establishing of any management program including chemical compounds for the pest control, it is an important to know the effect of the used compounds on the population growth of the target pest. Population growth can be estimated by life tables because they synthesize data on reproduction and mortality of population. Thus 
life tables are considered a powerful tool for clarifying and understanding the impact of an external factor upon the growth, survival, reproduction and rate of increase of an insect population (Birch 1948, Abou-Setta et al., 1986, Wittmeyer \& Coudron 2001 and El-Gemeiy 2002).

The present study was conducted to investigate the life table parameters of the pink bollworm, Pectinophora gossypiella (Saund.) treated as newly hatched larvae with some insecticides. The insecticides tested were recommended for controlling the cotton bollworms in Egypt i. e., esfenvalerate, fenpropathrin, lambda cyhalothrin, chlorpyrifos, thiodicarb and tebufenozide.

\section{MATERIALS AND METHODS}

A laboratory strain of the pink bollworm P.gossypiella (Saund.) was reared in the Integrated Pest Management Laboratory, Bollworms Department, Plant Protection Research Institute, Agricultural Research Center on modified artificial diet as described by Abdel-Hafez et al., (1982). The insect stages were reared for many successive generations.

\section{Tested compounds:}

\section{Synthetic pyrethroid compounds:}

1.1. Es fenvalerate (Sumi-alpha $5 \%$ EC.): (S)- a - cyano -3-phenoxy benzyl) (s) - 2(4-chlorophenyl)-3-methylbutyrate.

1.2. Fenpropathrin (Danitol $30 \%$ EC.): alpha-cyano- 3 - phenoxy phenyl methyl 2,2,3,3-tetra methyl cyclopropane carboxylate.

1.3. Lambda cyhalothrin (Karate $5 \%$ EC.): a reaction product comprising equal quantities of (S)-a- cyano-3- = phenoxy benzyl (z) -(1R)-cis-3-(2-chloro-3,3,3trifluoropropenyl)-2,2- = dimethyl cyclopropane carboxylate and (R)- a-cyano-3phenoxy benzyl (Z) - (1S) -cis-3-(2-chloro- =3,3,3-trifluoropropenyl)-2,2dimethyl cyclopropane carboxylate.

Organophosphorus compound: Chlorpyrifos (Dursban 48\% EC.) 0,0-diethyl 0-(3,5,6 trichloro -2- pyridinyl phosphorothioate.

\section{Carbamate compound:}

Thiodicarb (Larvin 80\% WP.): 3,7,9,13 - tetramethyl - 5,11-dioxa-2,8,14-trithia4,7,9,12- tetra- azapentadeca-3,12-diene-6,10-dione.

\section{Antimoulting compound:}

Tebufenozide (Memic 24\% FL.) : [ N - tetra - butyl - N - (4 - ethylbenzoyl) - 3,5 - dimethyl benzohydrazide]. 


\section{Life table parameters of certain insecticides of the pink bollworm treated as newly hatched larvae:}

The changes in the life table parameter of the pink bollworm after treatment as newly hatched larvae with the $L_{50}$ 'S of es fenvalerate, fenpropathrin, lambda cyhalothrin, chlorpyrifos, thiodicarb and tebufenozide were studied. Data were analyzed according to Birch (1948) using life 48 basic computer program by AbouSetta et al., 1986.

The program includes the following information for each interval of adult female age: total progeny per interval (egg laying rate) (M), number of females alive at age $X$ $(L)$, mean female age at each interval mid-point $(X)$, female progeny per female produced during the day $X(M x)$, rate of survival $(L x)$, the product of $[(M x)(L x)]$ as $(M x L x)$, and the final values of RML (the product of $(M x)(L x)$ is then devided by the value of e (the base of natural logarithm) to the power of $\left[\left(r_{m}\right)(X)\right]$ ), finally, the program prints the precise life table parameters of this study as the sum of RML, the generation time $(T)$ was calculated by $[\Sigma((X)(L X)(M x)) / R o]$, the net reproductive rate (Ro) was calculated by $[\Sigma((L x)(M x))]$, the doubling time (DT) which was resulted from divided the normal logarithm on $r_{m}$, the intrinsic rate of natural increase $\left(r_{m}\right)$ was calculated by $[\ln (R o) / T]$ and the finite rate of increase $\left(e^{r m}\right)$ is the natural antilogarithm of the intrinsic rate of increase and gives the number of times which the population multiplies in a unit time.

\section{RESULTS AND DISCUSSION}

The female progeny produced per female $(M x)$ and the rate of survival $(L x)$ of the pink bollworm after treatment as newly hatched larvae with esfenvalerate $\left(L C_{50}=0.0017 \mathrm{mg} / \mathrm{cm}^{2}\right)^{2}$, fenpropathrin $\left(L_{50}=0.0009 \mathrm{mg} / \mathrm{cm}^{2}\right)$, lambda cyhalothrin $\left(L C_{50}=0.0160 \mathrm{mg} / \mathrm{cm}^{2}\right)$, chlorpyrifos $\left(L C_{50}=0.0210 \mathrm{mg} / \mathrm{cm}^{2}\right)$, thiodicarb $\left(L_{50}=0.0620\right.$ $\left.\mathrm{mg} / \mathrm{cm}^{2}\right)$ and tebufenozide $\left(\mathrm{LC}_{50}=1.0560 \mathrm{mg} / \mathrm{cm}^{2}\right)$ were illustrated in figures $(1,2 \& 3)$. Generally, great progeny were produced per female with the first 10 days of their life time.

As shown in figure (1), fenpropathrin gave the highest effect when the newly hatched larvae were treated with this compound compared with the other tested compounds, Mx parameter (female progeny per female) ranged between 0.54 to 7.10 female progeny/female compared with the control values which ranged between 0.18 to 14.84 female progeny /female as illustrated in figure (3). On the other hand, Lx parameter (rate of survival) ranged between 0.17 to 0.50 times as shown in figure (1) as compared with the control values which ranged between 0.29 to 0.93 times. 
Figure 1. Female progeny per female (Mx) and survival rate (Lx) of P.gossypiella treated as newly hatched larvae with $L C_{50}$ 'S of es fenvalerate, fenpropathrin and lambda cyhalothrin.
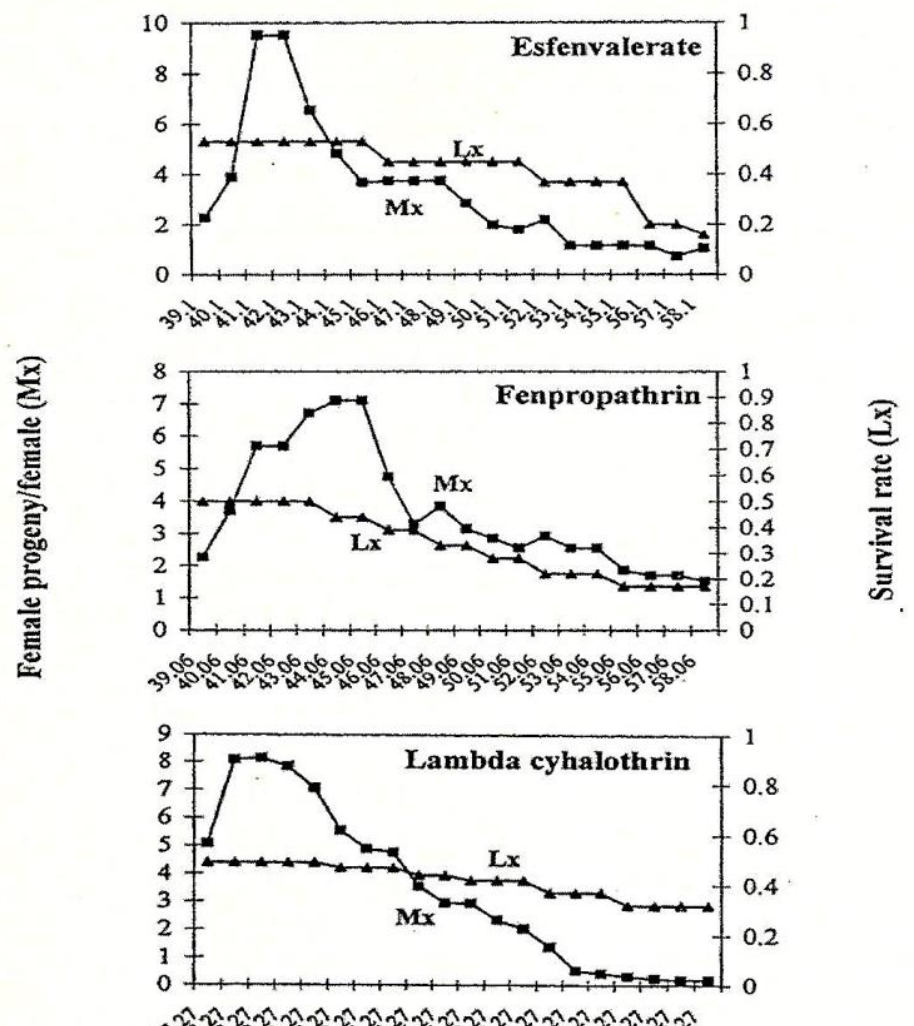

की

Actual female age (in days)

$\rightarrow-M x$

$-\mathrm{Lx}$

Es fenvalerate 
Figure 2. Female progeny per female (Mx) and survival rate (Lx) of P.gossypiella treated as newly hatched larvae with $\mathrm{LC}_{50}$ 'S of chlorpyrifos and thiodicarb.

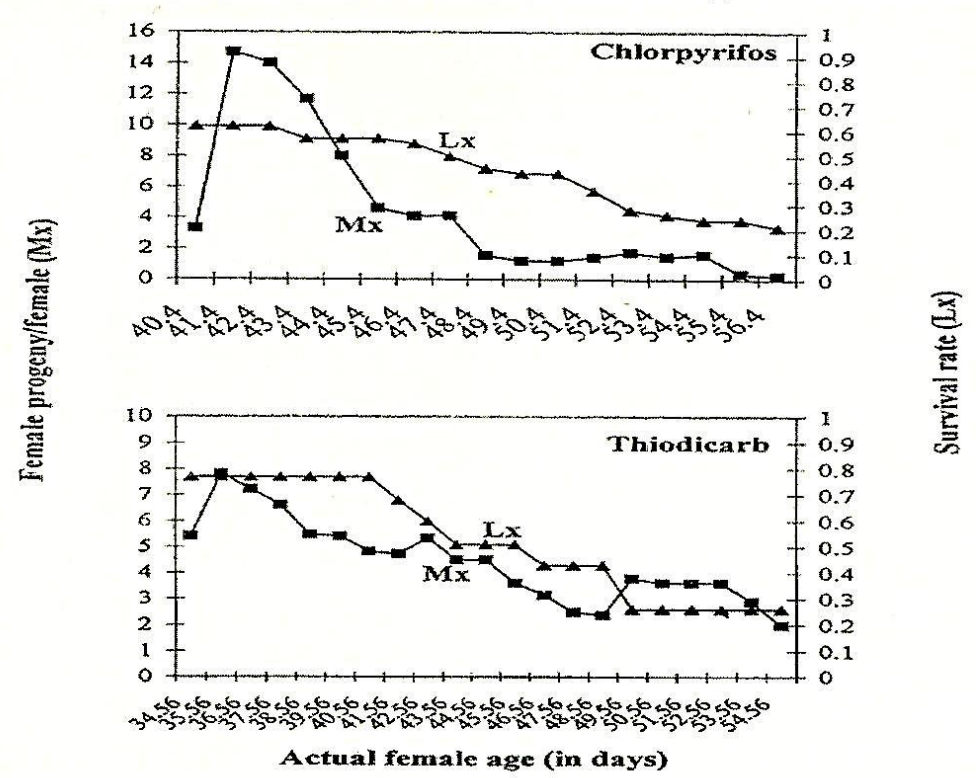

$\rightarrow-M x \quad-\infty-1 x$

Figure 3. Female progeny per female $(M x)$ and survival rate $(L x)$ of P.gossypiella treated as newly hatched larvae with $L_{50}$ 'S of tebufenozide and control.

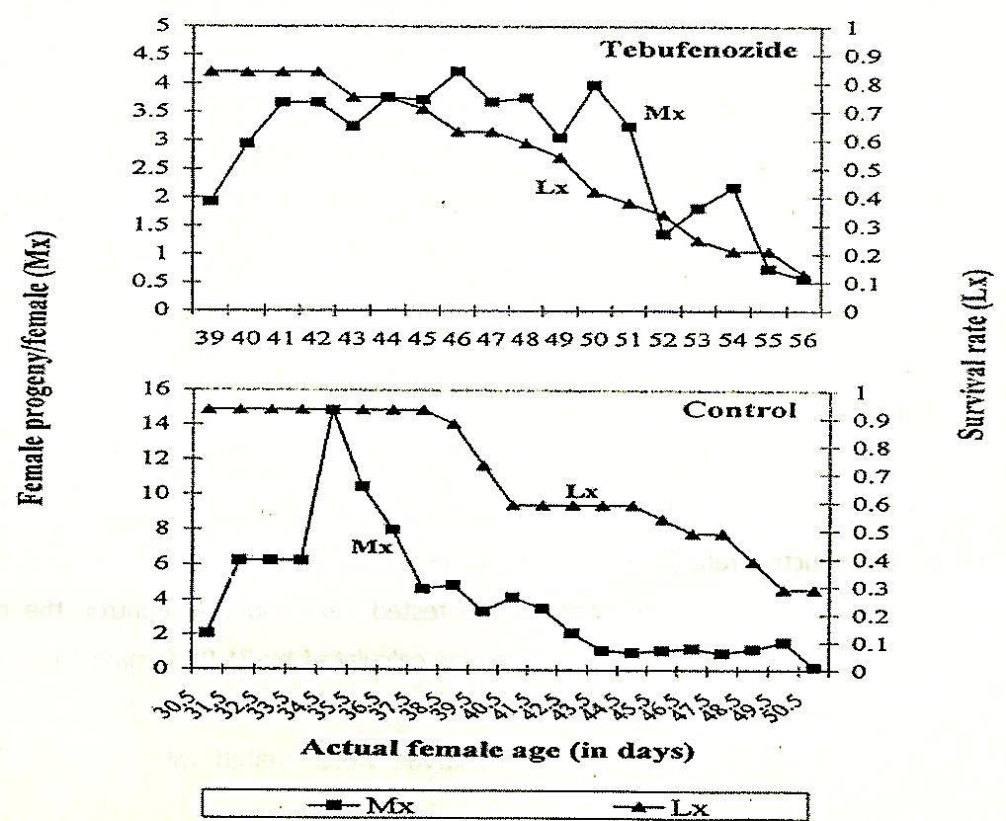


Figure (3) showed that Mx parameter of tebufenozide ranged between 0.57 to 4.21 female progeny/female, and $L x$ parameter for tebufenozide ranged between 0.13 to 0.84 times compared with the control values.

Also, esfenvalerate in figure (1) showed that highly effect on $M x$ parameter that was decreased and ranged between 0.73 to 9.52 female progeny/female. In addition, Lx parameter decreased between 0.16 to 0.53 times as compared with the control values. In this respect Abdel-Rahman et al. (2002) showed that the treatment of eggs, larvae, pupae and adult moths with $\mathrm{LC}_{50}$ of esfenvalerate caused prolonging effects on the larval and pupal durations, adult life span and oviposition period. The tested insecticide reduced the fecundity of female moths and hatchability of deposited eggs, this effect was reflected in high percentages of sterility.

Mx parameter of lambda cyhalothrin ranged between 0.21 to 8.16 female progeny/female, while $L x$ parameter ranged between 0.32 to 0.49 times as shown in figure (1). Also, Mx parameter of chlorpyrifos ranged between 0.24 to 14.70 female progeny/female, while $L x$ parameter ranged between 0.21 to 0.62 times as shown in figure (2). On the other hand, Mx parameter of thiodicarb ranged between 1.99 to 7.82 female progeny/female, also Lx parameter ranged between 0.26 to 0.77 times as shown in figure (2) as compared with the control values.

The five main parameters associated with a fertility life table are the mean generation time $(T)$, the net reproductive rate (Ro), doubling time (DT), the intrinsic rate of natural increase $\left(r_{m}\right)$ and the finite rate of increase $\left(e^{r m}\right)$ as in Table (1).

1. Generation time $(T)$ :

Concerning the control, the generation time lasted 35.35 days as represented in Table (1) and fig. (4). While this period was prolonged as a result of treatment to newly hatched larvae with the $\mathrm{LC}_{50(\mathrm{~s})}$ of the tested insecticides. The maximum mean of generation time occurred in fenpropathrin (44.52 days), tebufenozide (44.43 days) and esfenvalerate ( 44.05 days) followed by chlorypyrifos (43.57 days), lambadacyhalothrin (41.57 days) and then thiodicarb (39.64 days).

\section{Net reproductive rate (Ro):}

Regarding the results in shown in Table (1) and fig. (4), it was very clear that the adverse effect of the tested insecticides was expanded to the produced females, as the net reproductive rate (Ro) of those females was greatly reduced. Moreover, the adverse effect was differed according to the tested insecticide. At control, the net reproductive rate (Ro) of the pink bollworm was calculated by 71.05 females/ female, while it was drastically reduced to be $28.23,31.43,32.11,32.99,41.54$ and 54.17 females/ female when the newly hatched larvae were treated with the $\mathrm{LC}_{50(\mathrm{~s})}$ of 
fenpropathrin, tebufenozide, esfenvalerate, lambda cyhalothrin, chlorpyrifos and thiodicarb, respectively.

\section{Doubling Time (DT):}

At any population, the time of generation doubling is depending directly on the intrinsic rate of natural increase $\left(r_{m}\right)$, which is affected by many factors such as the rate of survival, the time of generation, female progeny and females fecundity. In control, the pink bollworm population had the capacity to multiply every 5.747 days Table (1) and fig. (4). However, this population had the capacity to double every $9.238,8.932 ; 8.802,8.314,8.104$ and 6.883 days when the newly hatched larvae treated with the $\mathrm{LC}_{50(\mathrm{~s})}$ of fenpropathrin, tebufenozide, esfenvalerate, lambdacyhalothrin, chlorpyrifos and thiodicarb, respectively.

\section{4- Increase rate:}

\subsection{Intrinsic rate of natural increase $\left(r_{m}\right)$ :}

The calculated life table parameters in Table (1) and fig. (5) revealed that daily intrinsic rate of natural increase $\left(r_{m}\right)$ greatly affected by the treatment of the pink bollworm with

Table 1. Life Table parameters of $P$. gossypiella treated as newly hatched larvae with $\mathrm{LC}_{50}$ 's of tested insecticides.

\begin{tabular}{|c|c|c|c|c|c|}
\hline \multirow{2}{*}{ Treatments } & \multirow{2}{*}{$\mathrm{T}$ (days) } & \multirow{2}{*}{$\left(R_{0}\right)$} & \multirow{2}{*}{ DT(days) } & \multicolumn{2}{|c|}{ Increase rate } \\
\hline & & & & $\left(r_{m}\right)$ & $\left(\mathrm{e}^{\mathrm{m} m}\right)$ \\
\hline Esfenvalerate & 44.05 & 32.11 & 8.802 & 0.079 & 1.082 \\
\hline Fenpropathrin & 44.52 & 28.23 & 9.238 & 0.075 & 1.078 \\
\hline Lambda cyhalothrin & 41.57 & 32.99 & 8.314 & 0.083 & 1.086 \\
\hline Chlorpyrifos & 43.57 & 41.54 & 8.104 & 0.086 & \begin{tabular}{l|l}
1.089 \\
\end{tabular} \\
\hline Thiodicarb & 39.64 & 54.17 & 6.883 & 0.101 & 1.106 \\
\hline Tebufenozide & 44.43 & 31.43 & 8.932 & 0.078 & 1.081 \\
\hline Control & 35.35 & 71.05 & 5.747 & 0.121 & \begin{tabular}{l|l}
1.128 \\
\end{tabular} \\
\hline
\end{tabular}
$(\mathrm{T})=$ Generation time
$\left(R_{0}\right)=$ Net reproductive rate
$(\mathrm{DT})=$ Doubling time
$\left(r_{m}\right)=$ Intrinsic rate of natural increase 
Figure 4. Life table parameters (T, Ro\& DT) of P.gossypiella treated as newly hatched larvae with $\mathrm{LC}_{50}$ 'S of tested insecticides.
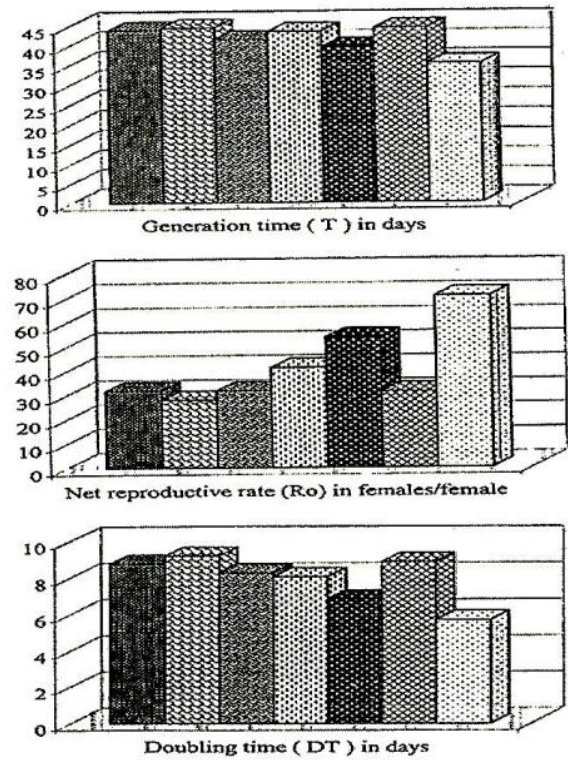

$\begin{array}{lll}\text { Esfenvalerate } & \text { Eenpropathrin Lambda cyhalothrin } \\ \text { E3 Chlorpyrifos } & \text { Thiodicarb }\end{array}$

口 Control

the $\mathrm{LC}_{50(\mathrm{~s})}$ of the six tested insecticides. In control, the $r_{\mathrm{m}}$ values were 0.121 times/female/day. These values were decreased to $0.075,0.078,0.079,0.083,0.086$ $\& 0.101$

times/female/day when the newly hatched larvae were treated with fenpropathrin, tebufenozide, esfenvalerate, lambda cyhalothrin, chlorpyrifos and thiodicarb, respectively.

\subsection{Finite rate of increase $\left(e^{\mathrm{rm}}\right)$ :}

Data illustrated in Table (1) and fig. (5) represented the finite rate of increase $\left(\mathrm{e}^{\mathrm{rm}}\right)$. The population of the pink bollworm had the capacity of increase by 1.128 times/female/day for the control. These values were greatly affected in relation to the tested insecticides. The capacity of population increase were 1.078, 1.081, 1.082, $1.086,1.089 \& 1.106$ times/female/day when the newly hatched larvae were treated with fenpropathrin, tebufenozide, esfenvalerate, lambda cyhalothrin, chlorpyrifos and thiodicarb, respectively.

Es fenvalerate Es fenvalerate 
In conclusion, the six tested compounds could be classified into three categories based on their efficacy on the pink bollworm life table parameters as following:

1- The first category represented insecticides having a highly effect i.e. fenpropathrin, followed by tebufenozide.

2- The second category represented insecticides that revealed a moderately effect as compared with the first category. This category included esfenvalerate, lambda cyhalothrin and chlorpyrifos.

3- The third category was thiodicarb that showed the least insecticidal action.

Figure 5. Life table parameters $\left(r_{m} \& \mathrm{e}^{\mathrm{m}}\right)$ of P.gossypiella treated as newly hatched larvae with $\mathrm{LC}_{50}$ 's of tested insecticides.
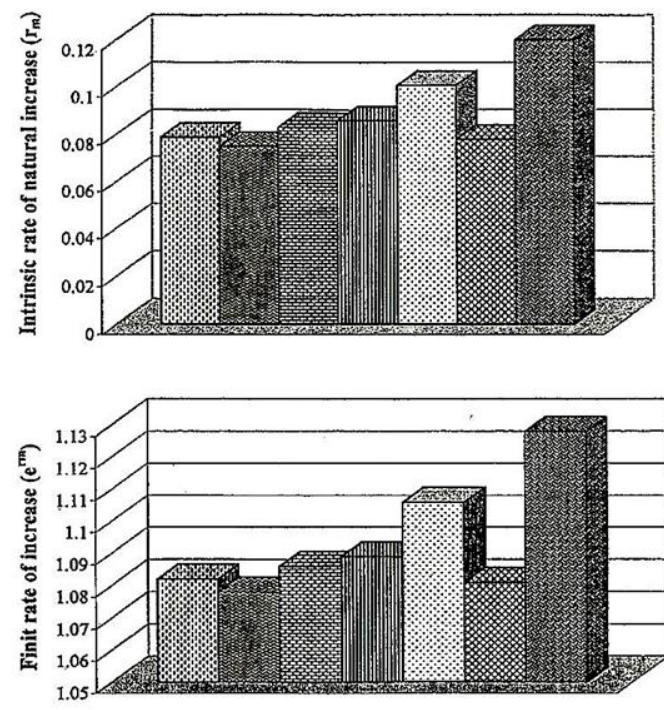

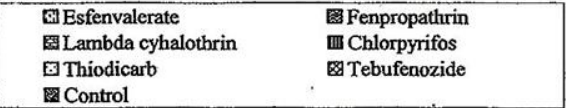


Various workers had used life table analysis defined as the stimulatory effect of sublethal concentrations of insecticides as Draz (1985) who carried out laboratory experiment on certain biological aspects of S.ocellatella and found that, the eggs were laid individually on heart-leaf and petioles. The incubation period and hatchability percent were 4.93 days and $98.3 \%$, respectively. The percentage of survivor eggs, larvae and pupae were $98.33,89.8$ and $92.45 \%$, respectively. The sex ratio $(0.571)$ was estimated as a number of females in proportion to the total population. The longevity of adult moths were 14.3 days for males and 15.7 days for females.The net reproductive rate $(R o=34.98)$, the generation duration in days (35.86 days), $r_{m}=$ 09911073 and $e^{r m}=1.104189$. Saadany and Hamed (1985) conducted laboratory life table studies to varify the relative suitability of 3 plants (cotton, berseem and castoroil) to the cotton leafworm, Spodoptera littoralis (Boisd.). The daily mortality and fecundity rates, the net reproductive rate and the instantaneous population increase could be worked out for each host. Larval mortality was comparatively higher on cotton whereas, net reproductive rate and instantaneous rate of population increase were higher on berseem than on either castor-oil or cotton. In other words, higher numbers of female per day were laid on berseem. Sarichai (1991) stated that population dynamics of the castor semilooper, Achaea janata Linn. (Noctuidae: Lepidoptera) and its control were carried out under laboratory and field conditions at Suwan Farm, Nakhon Ratchasima. This study included population dynamics and chemical control of castor semilooper. Biological and partial ecological life table of castor semilooper were constructed. The spatial pattern of distribution of $A$. janata was contigious and the regression line between the population of castor semilooper and rainfall was $y=247.41-4.57 x$. Toxicity tested by leaf dipping method, indicated that carbaryl, methomyl, cypermethrin and carbosulfan were highly toxic for the control of the first and second instar larvae, but monocrotophos was highly toxic for the first instar larvae and was moderately toxic for the second instar larvae of castor semilooper bases on their $\mathrm{LC}_{50}$. In field conditions, all insecticides used on castor semilooper gave satisfactory control. There were no difference between insecticides, but results differed from the untreated subjects. Life table analysis yielded the following population parameters: the net reproductive rate $(\mathrm{Ro})=76.2272$ the cohort generation time $(T)=34.6756$, the capacity for increase $(R o)=0.7876$ and the finite rate of increase $($ lambda $)=2.1981$. 


\section{REFERENCES}

1. Abdel-Hafez, A., A. G. Metwally and M.R.A.Saleh. 1982. Rearing of bollworm, P.gossypiella on kidney bean diet in Egypt (Lepidoptera:Gelechiidae). Res. Bull. Fac. Agric., Zagazig Univ., No. 576.

2. Abdel-Rahman, H. A., Z. H. Zidan, W. M. El-Deeb, M. S. Salama and E. M. Radwan (2002): Insecticidal and delayed biological activities of esfenvalerate and abamectin on the spiny bollworm, Earias insulana (Boisd.). The first Conf. of The Central Agric. Pesticide Lab.,3-5 Sept..

3. Abou-Setta, M. M., R. W. Sorrel and C. C. Childers. 1986. Life 48: A basic computer program to calculate life table parameters for an insect or mite species. Florida Entomol. 69 (4): 690-697.

4. Birch, L. C. 1948. The intrinsic rate of natural increase of an insect population. J. Anim. Ecol., 17: 15-26.

5. Draz, K. A. 1985. A static life table for the sugar beet moth Scrobipalpa ocellatella (Boyd.) (Gelechiidae: Lepidoptera) on sugar beet. $2^{\text {nd }}$ Nat.Conf.of Pests\& Dis. of Veg.\& Fruits Ismailia.

6. El-Gemeiy, H. M. 2002. Impact of two formulations of Bacillus thuringiensis var kurstaki on life table parameters of the spiny bollworm Earias insulana (Boisd.). Ann. Agric. Sc. Moshtohor, 40(3): 1753-1760.

7. Saadany, G. B. and A.A. Hamed. 1985. Life table studies on the cotton leafworm, Spodoptera littoralis (Boisd.) on three different host plants. $2^{\text {nd }}$ Nat.Conf.of Pests\& Dis. of Veg.\& Fruits Ismailia.

8. Sarichai, T. A. 1991. Population dynamics of castor semilooper (Achae janata Linn.) (Noctuidae:Lepidoptera) and its control. Bangkok (Thailand). 57 leaves

9. Wittmeyer, J. L. and T. A. Coudron. 2001. Life Table parameters, reproductive rate, intrinsic rate of increase, and estimated cost of rearing Podisus maculiventris (Say.) (Heteroptera: Pentatomidae) on an artificial diet. 'J. Econ. Entomol. 94(6): 1344-1352. 
تأثير بعض المبيدات على قياسات جذاول الحياه لاودة اللوز القرنقلية

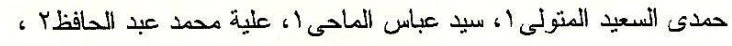

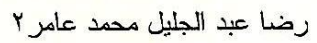

1. ثسم الحشرات الإقتصادية و المبيدات - كلية الزراعة- جامعة القاهرة- الجيزة- ج.م.ع.

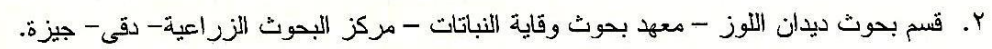

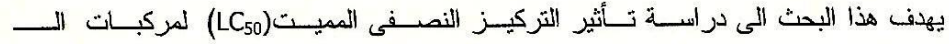

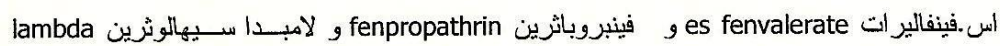

chlorpyrifos من مجمو عة البيرثرويدات المخلقة صناعيا و مركب الكلوروبيريفـوستورئ cyhalothrin

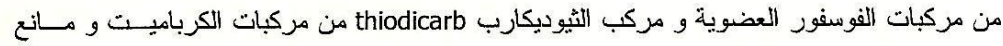

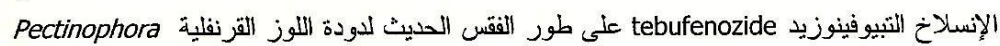

gossypiella (Saund.)

تم حساب قياسات جداول الحياه باستخدام برنامج الحاسب الآلى الذى أعده

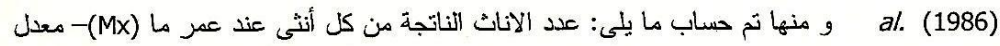

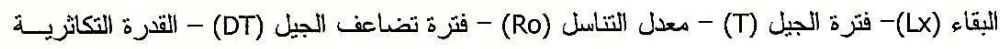

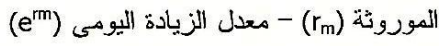

وقد أوضحت النتائج الآتى:

أعطى القينبروباتزين يليه التبيوفينوزيد أعلى إنخفاض فى عدد الاناث الناتجة من كل أنثى (Mx)

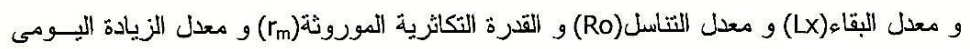

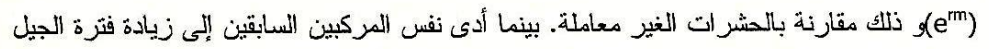

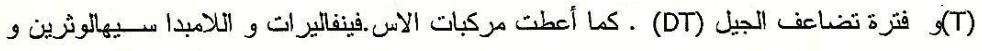

الكلوربيريفوس تأثير ا متوسطا بينما أعطى مركب الثيوديكارب أقل تأثير مقارنة بالمركبات السابقة. 